\title{
Study on the Production Mode of Horizontal Well from Water Huff and Puff to Segmented Injection and Production in Tight Reservoir
}

\author{
Shiying Di $\mathbb{D}$, ${ }^{1}$ Shiqing Cheng $\mathbb{D},{ }^{1}$ Cao Wei $\mathbb{D}^{1}{ }^{1}$ Wenpeng Bai $\mathbb{D},{ }^{1}$ Ruyuan Shang $\mathbb{D}$, ${ }^{1}$ \\ Nai Cao $\mathbb{i},{ }^{2}$ and Youpeng Zhang $\mathbb{D}^{1}$ \\ ${ }^{1}$ China University of Petroleum, Beijing 102249, China \\ ${ }^{2}$ Sinopec Research Institute of Petroleum Engineering, Beijing 100101, China \\ Correspondence should be addressed to Shiqing Cheng; chengsq973@163.com and Wenpeng Bai; 2020210314@student.cup.edu.cn
}

Received 17 April 2021; Accepted 8 May 2021; Published 14 June 2021

Academic Editor: Tianran Ma

Copyright (c) 2021 Shiying Di et al. This is an open access article distributed under the Creative Commons Attribution License, which permits unrestricted use, distribution, and reproduction in any medium, provided the original work is properly cited.

Water huff and puff in horizontal wells in tight reservoirs has achieved good results in replenishing formation energy. However, after multiple rounds of treatment, a rapid decrease in formation pressure takes place making it difficult to maintain stable production. To improve the oil recovery rate of tight reservoirs, it is imminent to change the development mode. In this work, the stress distribution characteristics at fracture tips were analyzed based on Irwin theory and elastic theory. A model of propagation and closure length of fractures was established based on the propagation mechanism of water injection-induced natural fracture and the energy balance principle of fracture mechanics. Surfactant imbibition experiments were carried out according to the imbibition principle of surfactant system, and the propagation law of natural fractures was described with numerical simulation to analyze the seepage characteristics of dynamic fracture network. On the basis of the above works, alternating water huff and puff into segmented injection and production was proposed according to the distribution law of dynamic fracture network. The developing process of an actual well case by these two developing modes was simulated to predict 18 years of cumulative recovery, pressure distribution, and recovery rate. Results showed that when stress intensity factor exceeds the fracture toughness, the natural fractures will extend along their original directions and get connected, forming an irregular fracture network. The lengths of fractures after propagation and closure will not bring about water channeling for they are far shorter than well and interval spacing. Surfactant could diminish the resistance of boundary layer by reducing the wetting contact angle, ending up with an improvement in imbibition efficiency. Radial displacement and dynamic imbibition occur simultaneously in a dynamic fracture network during the early stage of water injection, while static imbibition mainly occurs during injection shutdown period and well soaking. According to comparison, the swept area of segmented injection and production was larger, ending up with a continuous increase of simulated recovery rate and cumulative recovery. The findings of this study show alternating water huff and puff after to segmented injection and production in fractured tight reservoir can allow full play of dynamic fracture network's potential and achieve effective enhancement in oil recovery rate.

\section{Introduction}

Since the tests of water huff and puff development in tight reservoirs such as Changqing Tuha and Daqing have shown a good oil increasing effect in the early stage, the development effects have attached great importance [1,2]. In tight reservoirs with natural microfractures, nature fractures are unevenly distributed. In horizontal wells with relatively developed natural fractures, a complex fracture network is formed by expanded nature fractures induced by water injection, which greatly increases the velocity and quantity of fluid exchange between injected water and matrix [37]. As the crude oil continues to be produced, the fluid pressure in the reservoir will gradually decrease, and the effective stress acting on the fracture and matrix rock blocks will increase accordingly. The overall volume of the 
rock will then be compressed and reduced, resulting in partial closure of fractures, namely, the decrease of the flow conductivity. It is of great practical value to study the fracture closure length in determining the development mode of oilfield $[8,9]$. Due to the complex pore structure and low porosity and permeability of tight oil reservoirs, the injected fluid in fracture networks does not only interact with fluids but also exerts mutual viscous forces on the interface between fluid and matrix rock owing to a fluid boundary layer existing on near the pore wall [10]. The layer impedes the flow of fluids in the formation, thereby slowing its flow in the dynamic fracture network of tight reservoir $[11,12]$. Yang et al. verified that adding a drag reducer or reducing fluid viscosity and changing the properties of the rigid wall by increasing system temperature could reduce the effective boundary layer thickness and interaction force on injected water caused by rigid wall, thereby expanding the swept area of water injection [1315]. Remaining oil is enriched in areas with a low level of natural facture propagation and communication, for the swept area of injected water is narrow and the displacement and imbibition displacement are weak there [16-20]. Zongying believes that refracturing can restore the conductivity of natural fractures, reopen the existing fractures, or clean the natural fracture surface; namely, it can extend the natural fracture or produce ones [21]. Achieving economic benefits and improving the development effect with less cost require a change in the developing modes of oil fields. At present, there are some mature research works, such as reducing well spacing to improve injection-production ratio and transforming high water content wells into production wells to improve water flooding control degree [22-24]. Shiqing's team carried out research on asynchronous injection and production of single horizontal well in ultralow permeability reservoirs, transforming interwell displacement into displacement between fractures in single well, and verified the feasibility [25].

The above methods are seldom applied to horizontal wells in fractured tight oil reservoirs with no evident effect on fractured oil reservoirs, and the theoretical models need to be further improved. Based on the principle of natural fracture propagation induced by water injection and the energy balance principle of fracture mechanics, this paper deduced the fracture propagation and closure length by taking type I and type II composite fractures as an example. The radial displacement and imbibition of dynamic fracture network in tight reservoir were also analyzed, and surfactant was added to reduce the resistance of boundary layer, expanding the contact area between injected water and matrix and enhancing the displacement and imbibition effect. Based on the simulation of fracture propagation process and remaining oil distribution in fractured tight reservoirs, the authors proposed to set the horizontal well as both water injection end and oil production end, transforming water huff and puff into segmented injection and production. The feasibility of the proposed method was demonstrated with numerical simulation, which provides a basis for the development mode transformation for fractured tight reservoirs.

\section{Propagation Law of Natural Fracture Induced by Water Injection}

Natural fractures are stimulated to expand and extend when the pressure exceeds the fracture opening pressure and is lower than the rupture pressure in tight oil reservoir with natural microfractures. The connected microfractures will then form a new seepage space and increase the permeability and conductivity of tight reservoirs.

2.1. Propagation Law of Natural Fracture. Natural fractures already existed before the propagation of fracture induced by water injection, so the calculation of fracture propagation pressure for the $i$ th time is different from that for the first time.

The Irwin theory, which is formed by continuous enrichment and development of the brittle fracture theory proposed by Griffith, can be used to analyze the ith fracture propagation with the strength of the stress field near the fracture tip for the theory is mainly applicable to the analysis of the stress and strain field at the fracture tip in a small range. According to Irwin theory, natural fracture propagation is divided into three types: type I fracture opening, type II fracture cutting, and type III fracture tearing (Figure 1(a)) [26-29].

For natural fracture propagation induced by water injection, the situation that the injected water opens which was originally closed or filled natural fracture is regarded as type $I$ fracture. The situation that the fracture expands and extends forward simultaneously is regarded as type I and type II composite fractures (Figure 1(b)).

For type I and type II composite fractures, the fracture propagation should be determined according to the far-field stress state and fracture dip angle. The stress field of fracture tip can be abbreviated as

$$
\sigma_{i j}=\frac{K_{I}}{\sqrt{2 \pi r}} f_{i j}(\theta)+\frac{K_{I I}}{\sqrt{2 \pi r}} \phi_{i j}(\theta),
$$

where $\sigma$ is stress (MPa); $r$ is the polar radius of the control area of fracture tip (m); $\theta$ is the azimuth angle in the zone centered by the fracture tip $\left(^{\circ}\right) ; f_{i j}(\theta), \varphi_{i j}(\theta)$ are angle distribution functions; and $K$ is the stress intensity factor of fracture tip, which is referred to as stress intensity factor, $\mathrm{MPa}$ $\sqrt{\mathrm{m}}$. The value of $K$ for different formation can be obtained by experimental measurement or searching existing results. The stress intensity factor reflects fracture propagation ability, namely, the ability to resist brittle break; $K_{I C}$ is the critical value of $K$, which stands for fracture toughness. When $K>$ $K_{I C}$, the natural fractures expand, extend forward, and get connected, improving the fracture density and forming complex fracture network (Figure 2).

Water injection induces the expansion and extension of natural fractures and improves the conductivity of fracture network. In order to avoid water channeling, research on fracture propagation length is a matter of urgency. Calculation of fracture propagation length can help to identify and preclude water channeling. Assuming that each horizontal 


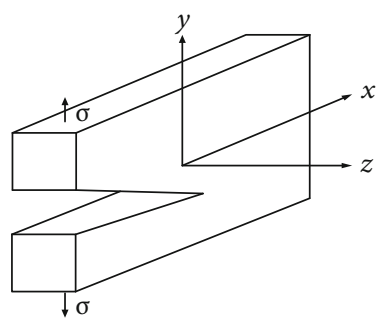

Type I fracture opening

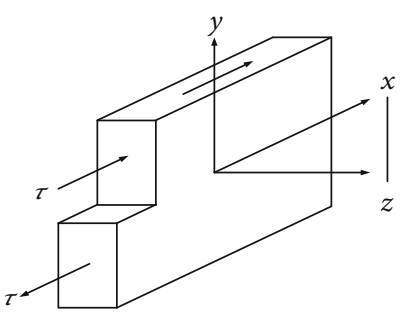

Type II fracture cutting

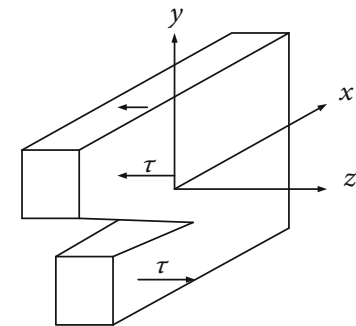

Type III fracture tearing

(a) Natural fracture propagation is divided into three types

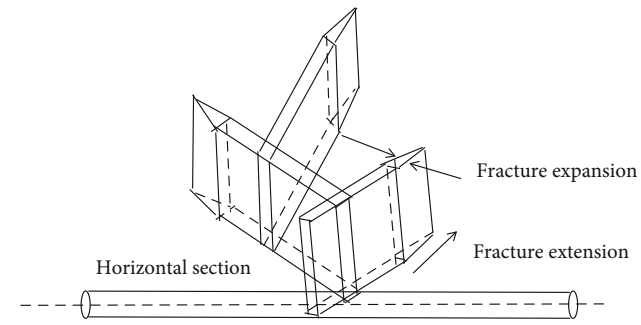

(b) Fracture expands and extends forward simultaneously

FIGURE 1: Fracture propagation model.

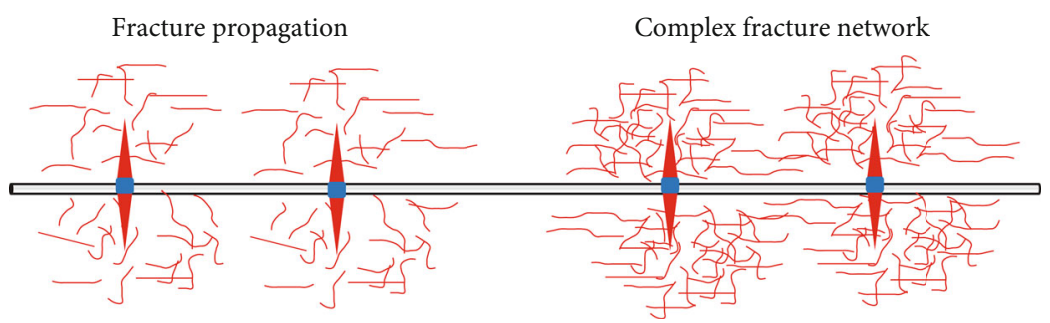

FIgURE 2: Complex fracture network formed by fracture propagation.

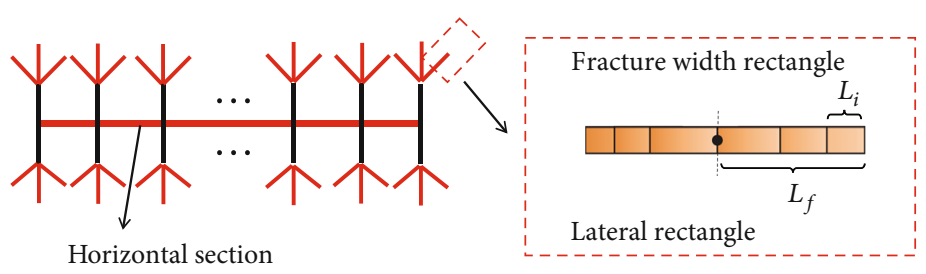

FIGURE 3: Diagram of fracture propagation length.

section has 10 levels of factures, each of which has 3 microfractures in both the ends of fractures, accounting 60 fractures in total (Figure 3). The propagation is shaped in cuboid, with the length for the $i$ th propagation as $L_{i}$ and the corresponding fracture half-length as $L_{f}$.

In this process, based on the energy balance principle of fracture mechanics adopted in Griffith criterion, the linear elastic solution of the whole system from the moment old fractures formed with no fluid yet filled into the moment new fractures generated with no fluid filled in is obtained as follows:

$$
\Delta E_{i}=\Delta E_{l i}+\Delta E_{f i}+\Delta E_{r s_{i+1}}+\Delta E_{i c_{i+1}}
$$

where $\Delta E_{i}$ represents the energy flowing into the ground, $\Delta E_{l}$ is the energy filtered, $\Delta E_{f}$ is the elastic energy in the fracture,
$\Delta E_{r s}$ is the elastic energy in the matrix, and $\Delta E_{i c}$ is the energy of new fracture.

The expression of the energy inflow from the ground $\Delta E_{i}$ is

$$
\Delta E_{i}=\int_{T \mathrm{i} 0}^{T i} P(t) Q d t
$$

The expression for the energy lost by filtration $\Delta E_{l i}$ is

$$
\Delta E_{l i}=120 \times \sum_{j=1}^{\mathrm{i}} \int_{T \mathrm{i} 0}^{T i}\left[P(t)+P_{H}-P_{P}\right] \times \frac{\mathrm{C}(t)}{\sqrt{t}} A_{j} d t .
$$




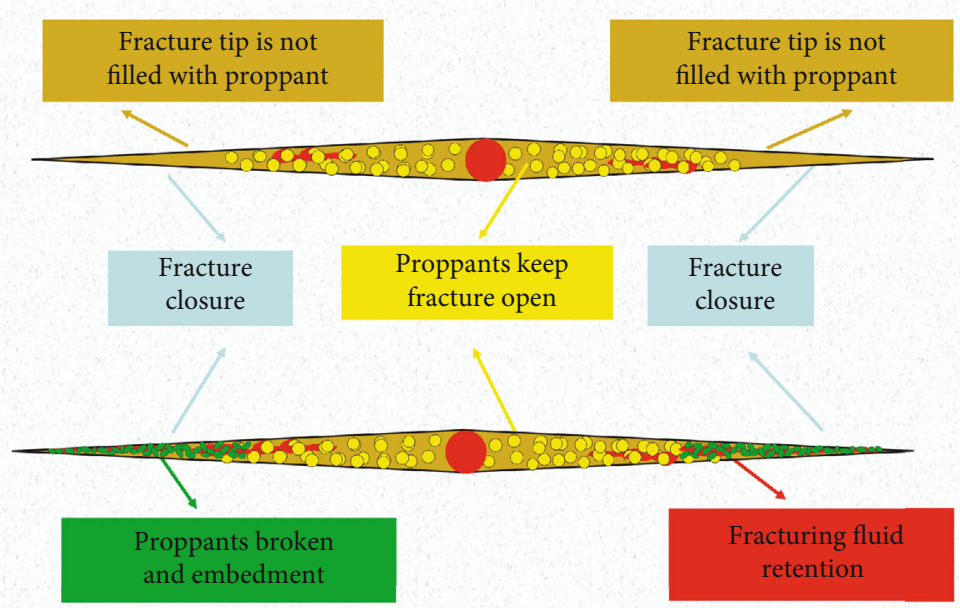

FIGURE 4: The position of fracture closure.

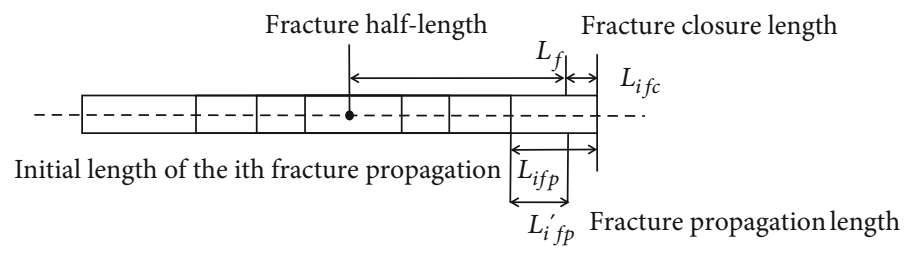

Figure 5: The composition of fracture length change.

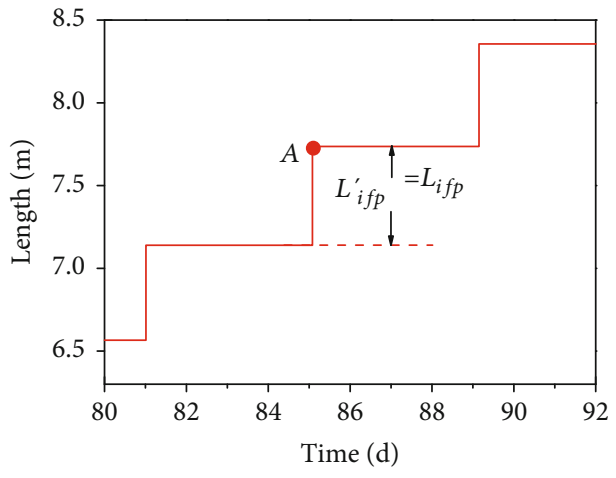

(a) Without consideration of fracture closure

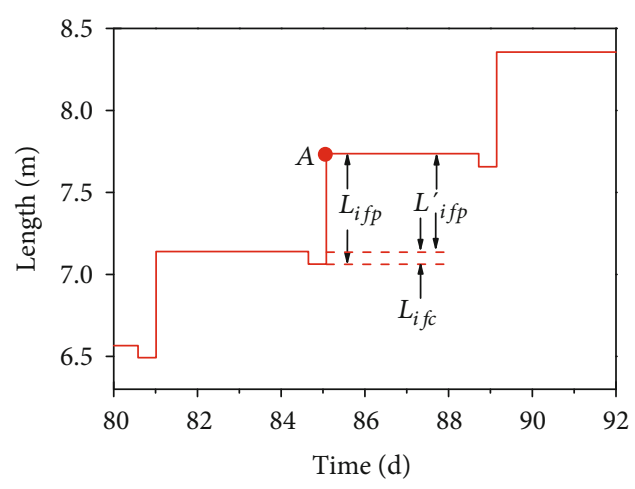

(b) With consideration of fracture closure

FIgURE 6: Comparison of fracture propagation length with and without consideration of fracture closure.

The expression of elastic energy in the slit $\Delta E_{f i}$ is

$$
\Delta E_{f i}=120 \times\left(P-P_{H}-P_{i 0}\right) \times \omega \times H \times L_{i} .
$$

The elastic energy stored in the matrix can be overcame according to the Griffith criterion.
The expression of the elastic energy in the matrix $\Delta E_{r s_{i+1}}$ is

$$
\Delta E_{r s_{i+1}}=\frac{\pi \sigma_{h}^{2}\left(60 A_{i+1}\right)}{16 E H} .
$$

The energy absorbed by the new fracture surface $\Delta E_{i c_{i+1}}$ is.

$$
\Delta E_{\mathrm{i}_{i+1}}=120 \times A_{i+1} \times \gamma .
$$




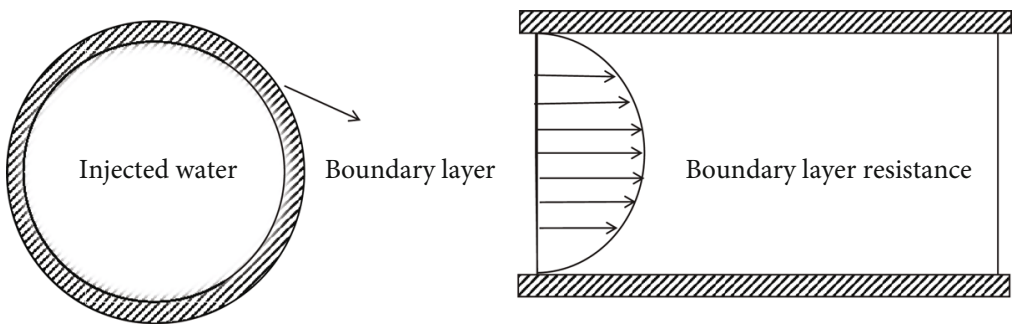

Figure 7: Function of boundary layer.

The energy balance equation in the whole system of fracture propagation is expressed as

$$
\begin{aligned}
\int_{T \mathrm{i} 0}^{T i} P(t) Q d t= & 120 \times \sum_{j=1}^{i} \int_{T i 0}^{T i}\left[P(t)+P_{H}-P_{P}\right] \times \frac{C(t)}{\sqrt{t}} A_{j} d t \\
& +120 \times\left(P-P_{H}-P_{i 0}\right) \times \omega \times H \times L_{i} \\
& +\frac{\pi \sigma_{h}^{2}\left(60 A_{i+1}\right)}{16 E H}+120 \times A_{i+1} \times \gamma .
\end{aligned}
$$

According to the actual block, the filtration coefficient $C(t)$ can be expressed as

$$
C(t)=-9.27 x+10.905
$$

where $Q$ is the injection rate $\left(\mathrm{m}^{3}\right), L_{i}$ is the half-length of the $i$ th fracture propagation $(\mathrm{m}), P_{P}$ is formation pore pressure $(\mathrm{MPa})$, $P$ is the density of injected fluid $\left(\mathrm{kg} / \mathrm{m}^{3}\right), P_{H}$ is the pressure caused by wellbore fluid column (MPa), $A_{i+1}$ is the lateral area of the half-length of the $i+1$ th fracture propagation $\left(\mathrm{m}^{2}\right), \sigma_{h}$ is the minimum horizontal principal stress (MPa), $E$ is the elastic modulus of formation rock ( $\mathrm{MPa}), H$ is reservoir thickness $(\mathrm{m}), \gamma$ is surface energy density $\left(\mathrm{MPa} / \mathrm{m}^{2}\right), C(t)$ is the filtration coefficient after fracture propagation $\left(\mathrm{m} / \mathrm{d}^{1 / 2}\right)$.

The fracture propagation length $L_{i}$ can be obtained from Equation (9). With continuous production of crude oil, the fluid pressure in the reservoir will gradually decrease, and the effective stress acting on the fracture and matrix rock blocks will increase accordingly. According to the research of domestic and foreign scholars on fracture closure law, the effective stress of hydraulic fracture increases to a certain extent which will lead to fracture closure from the microscopic perspective. It is difficult for sand-carrying fluid or displacement fluid to fully fill the far well fracture segment near the fracture end in the process of hydraulic fracturing, resulting in insufficient proppant in the far well fracture segment, which leads to the continuous increase of effective stress in the far well fracture segment and the partial fracture closure. Fracture closure have another reasons. The fracture is partially closed due to proppant rupture, fracturing fluid retention, etc. (Figure 4).

Such phenomena as partial fracture closure lead to complex changes in fracture conductivity, which increases the difficulty of accurately describing fracture conductivity. The remaining oil and gas in the matrix rock will become more difficult to recover, which will increase the cost of producing oil and gas in these blocks. It is conducive for productivity analy-

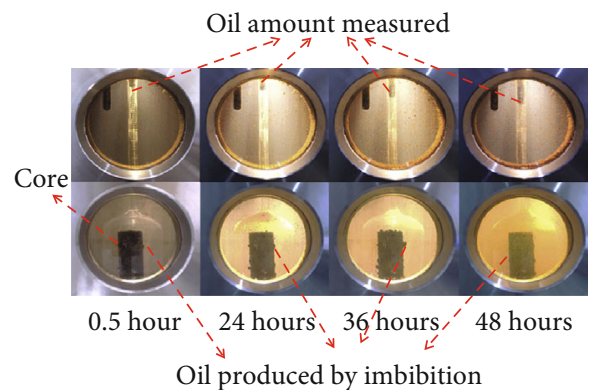

FIGURE 8: Imbibition process with surfactant added.

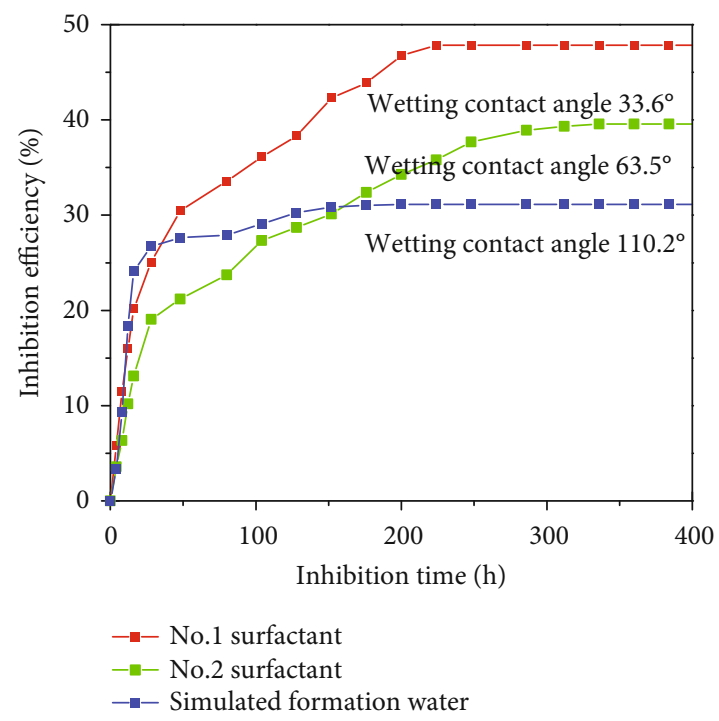

FIGURE 9: Influence on imbibition efficiency by different wetting contact angle.

sis and evaluation of the later development effect of the actual oilfield to study on fracture closure after fracture propagation, which is an urgent problem to be solved at present.

Based on the energy balance principle of fracture mechanics adopted in Griffith criterion, according to the composition of fractures in Figure 5, the closure length of fracture can be obtained by combining Equations (2) and (9).

$$
\begin{aligned}
2\left(P-P_{H}\right) w H L_{i f c} & =\frac{\pi \sigma_{h}^{2}\left(2 H \Delta L_{i+1 f c}\right)^{2}}{16 E H}, \\
L_{i f p}^{\prime} & =L_{i f p}-L_{i f \mathcal{c}}^{\prime},
\end{aligned}
$$




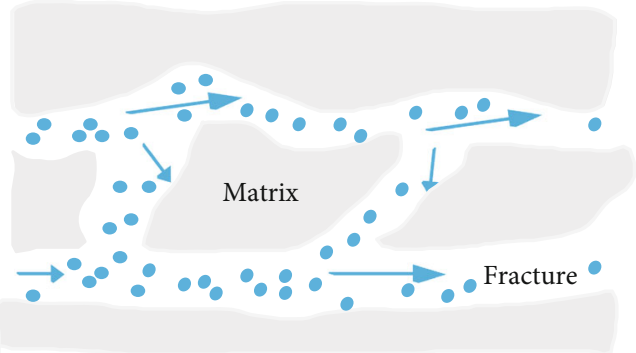

(a) Displacement function

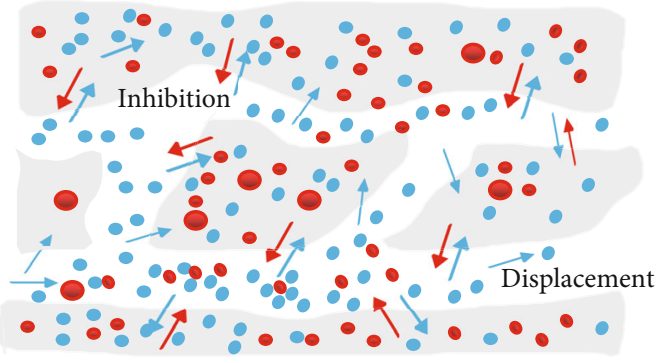

(b) Dual function of displacement and imbibition

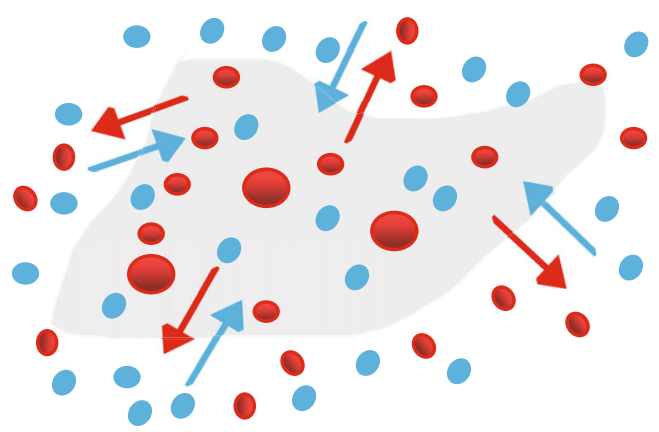

(c) Imbibition function

Figure 10: Principle of segmented injection and production.

where $L_{i f p}$ is the initial length of the $i$ th fracture propagation (m), $L_{i f c}$ is the length of fracture closure in the $i$ th fracture propagation process $(\mathrm{m}), L_{i f c}{ }^{\prime}$ is the fracture length after the $i$ th fracture propagation and closure, $\mathrm{m}$.

Larger decrease in reservoir fluid pressure will make it easier for fracture closure. Accurate calculation of fracture half-length after each fracture propagation is helpful in calculating the swept area and crude oil imbibition volume of dynamic fracture network, which is the key to effective utilization of water injection-induced fracture propagation and development scheme determination.

The half-length after the $i$ th fracture propagation in a tight reservoir is calculated. The calculated $L_{i f p}$ for point A without consideration of fracture closure is $0.72 \mathrm{~m}$, and the fracture half-length is $7.22 \mathrm{~m}$ (Figure 6(a)). Considering fracture closure, the calculated $L_{i f p}^{\prime}$ for point $\mathrm{A}$ is 0.41 , the $L_{i f c}$ is $0.31 \mathrm{~m}$, and the fracture half-length is $6.91 \mathrm{~m}$ (Figure 6(b)). The calculation result of actual oilfield suggested that $L_{i f p}^{\prime}<$ $L_{i f p}$, with a friendly match between simulated production and actual production.

2.2. Seepage Mechanism of Dynamic Fracture Network. Exploring the key mechanisms of water injection induces fracture propagation, fluid displacement and imbibition with matrix, and other complex phenomena and, thereby fundamentally grasping the seepage law of injected water in fractured tight reservoirs, is the key to improve the oil production.

After natural fracture propagation, fluid contacts with matrix through dynamic fracture network, and crude oil is

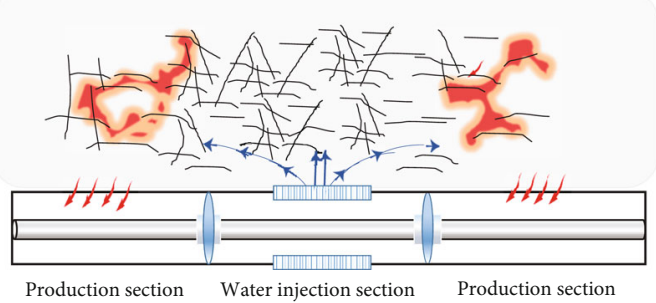

FIGURE 11: Diagram of segmented injection and production.

replaced by imbibition brought by capillary force. Fracture propagation leads to an increase in both permeability and water swept area. However, due to the complex pore structure and low porosity and permeability of tight oil reservoirs, the injected fluid in fracture networks does not only interact with fluids but also exerts mutual viscous forces on the interface between fluid and matrix rock owing to a fluid boundary layer existing on near the pore wall. The layer impedes the flow of fluids in the formation, thereby slowing its flow in the dynamic fracture network of tight reservoir and water swept area (Figure 7).

The displacement and imbibition efficiency are related to the rock wetting contact angle in a complex fracture network. Based on the modified Washburn equation [30, 31], an equation expressing the relationship between surface tension and wetting contact angle can be obtained.

$$
\theta_{r}=\cos ^{-1} \frac{-2 \mu \mathrm{s}}{\delta r},
$$




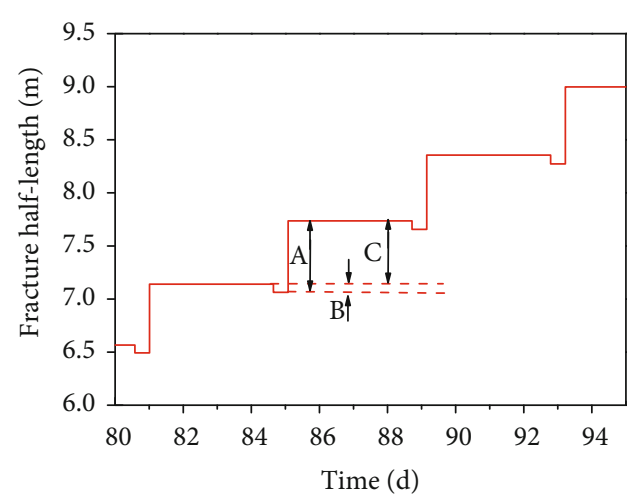

(a) Fracture propagation with time

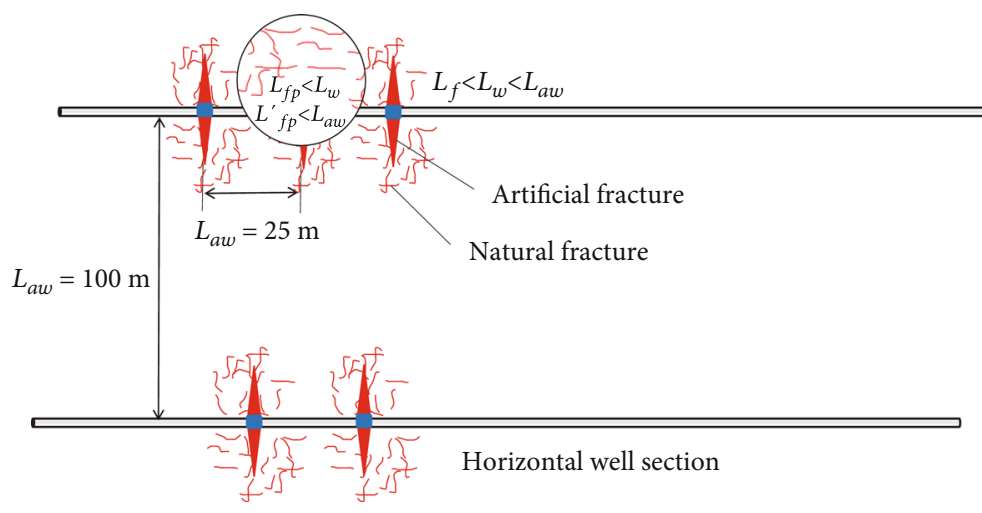

(b) Comparison of fracture propagation with well spacing and interval spacing

FIgURE 12: Diagram of calculation of fracture propagation and closure.

where $\theta_{r}$ is the wetting contact angle $\left(^{\circ}\right), \delta$ is the surface tension $(\mathrm{N} / \mathrm{m}), r$ is the pore radius of the matrix $(\mathrm{m}), \mu$ is viscosity $(\mathrm{Pa} \cdot \mathrm{s})$, and $s$ is the contact area $\left(\mathrm{m}^{2}\right)$.

According to Equation (11), the smaller the rock wetting contact angle, the weaker the interfacial tension between the fluid and the matrix rock block. In order to diminish the effect of interfacial tension between the fluid and matrix in a tight oil reservoir, surfactant imbibition experiments were carried out. The core saturated with crude oil was put into the test device according to formation environmental situation, and real-time observation on the core surface during the process was conducted (Figure 8). As the experiment proceeded, the oil produced from the core added surfactant was obviously more than that from core under formation water condition.

Compared with the imbibition experiment conducted according to formation water situation, the wetting contact angle became smaller after adding surfactant. The imbibition efficiency was the highest when the wetting contact angle of the surfactant added was $33.6^{\circ}$ (Figure 9 ). The results suggested that the surfactant reduces the interfacial tension between the fluid and matrix rock block, which decreases the hindrance caused by a boundary layer, resulting in a decrease in the resistance water displacement, an increase in fluidity, and an expansion in the radial displacement area. And the imbibition displacement and imbibition efficiency were enhanced with the increase of the fluid's contact area with matrix.

The addition of surfactant promoted the displacement and imbibition of the injected water in a fracture network. At the early stage of water injection, a dynamic fracture system formed by natural fracture propagation is taken as a favorable factor for water supply and oil flow, and radial displacement occurs during water injection (Figure 10(a)). As time goes on, the injected water enters the matrix to overcome the barrier effect of the boundary layer. With dual function of water injection pressure and capillary pressure, displacement and dynamic imbibition occur simultaneously to replace crude oil from a matrix into a seepage channel (Figure 10(b)). It is worth noting that static imbibition mainly occurs during injection shutdown and well soaking (Figure 10(c)).

\section{Segmented Injection and Production of Horizontal Well in Tight Oil Reservoirs}

It is of crucial importance to increase the swept area of injected water in the fracture system, thereby increasing its contact area with matrix, enhancing oil recovery by imbibition of the matrix, and further improving the production of remaining oil. In view of the problems of ineffective water injection and water channeling during the development of horizontal wells in reservoirs with permeability reservoirs, low permeability and extra-low permeability, the team of Shiqing Cheng has demonstrated the advantages of interfracture displacement and interfracture asynchronous injection and production with numerical simulation, innovated injection and production methods in single horizontal wells in 3 types of reservoirs, and designed corresponding techniques.

Based on that, the process of natural fracture propagation and the distribution of remaining oil in fractured tight reservoir were simulated in this work, according to the principle of natural fracture propagation induced by water injection and the theory of radial displacement and imbibition in a dynamic fracture network. On the grounds of the distribution characteristics of remaining oil and the propagation degree of fracture, the sections where natural fractures are well developed and dynamic fracture network is formed were set as water injection end, and the ones where fractures are poorly developed were set as oil production end. The injection and production ends were separated by packers, and their switch control was realized by controlling downhole tools.

Formation pressure and production decline rapidly in fractured tight reservoirs after multiple rounds of water huff and puff. Certain limitations existed in enhancing oil recovery effect by increasing the number of treating rounds. In order to alternate water huff and puff development, it is needed to take full advantages of the effect displacing system formed by high conductivity channel brought by the propagation of natural fractures. And in order to alleviate the blocking effect caused by boundary layer on fluid flow in tight reservoir formation, surfactant was added to the injected water to reduce interfacial tension, expand the contact area between injected water and matrix, and enhance the displacement and imbibition. 
TABLE 1: Schemes of segmented injection and production.

\begin{tabular}{lccccc}
\hline Program & Injection time $(\mathrm{d})$ & Soak time $(\mathrm{d})$ & Shut-in time $(\mathrm{d})$ & $\begin{array}{c}\text { Water } \\
\text { injection }\left(\mathrm{m}^{3} / \mathrm{d}\right)\end{array}$ & $\begin{array}{c}\text { Oil } \\
\text { production }\left(\mathrm{m}^{3} / \mathrm{d}\right)\end{array}$ \\
\hline 1 & 60 & 20 & 120 & 200 & 100 \\
2 & 120 & 15 & 80 & 100 & 100 \\
\hline
\end{tabular}

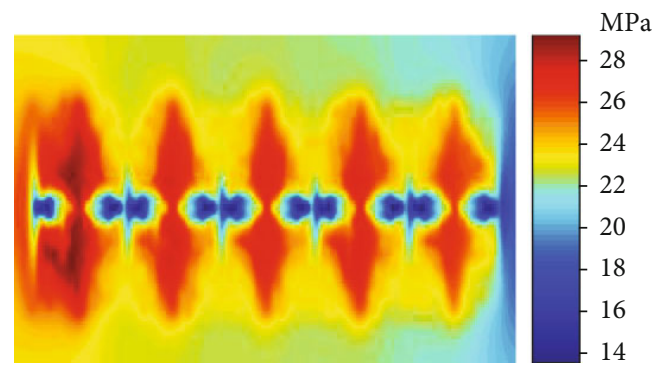

FIGURE 13: Water breakthrough occurred at $300 \mathrm{~m}^{3} / \mathrm{d}$ of water injection.

When the propagation length of fractures is far shorter than well spacing and interval spacing, no water channeling will occur (Figure 11). So to avoid water channeling, the propagation and closure of fracture should be carefully considered in the design of well and interval spacing. In a tight reservoir with a well spacing of $100 \mathrm{~m}$ and an interval spacing of $20 \mathrm{~m}, A$ is the $i$ th propagation length of natural fracture, $B$ is the $i$ th closure length of natural fracture, $C$ is the fracture length after its ith propagation. With Equations (3) and (4), the propagation length, closure length, and the actual length of fracture during water injection were calculated. For the $i$ th propagation, the calculation results were $L_{i f p}=0.67 \mathrm{~m}, L_{i f c}$ $=0.43 \mathrm{~m}, L_{i f c}{ }^{\prime}=0.24 \mathrm{~m}, L_{\text {if }}=7.66 \mathrm{~m}$. All these lengths in each fracture propagation were shorter than the well spacing and interval spacing, which assured no water channeling between the horizontal well section $L_{w}$ and adjacent wells $L_{a w}$ (Figure 12(b))

Taking the M56-152H well group as an example, 2 schemes were designed, respectively (Table 1). The injection time was set as $60 \mathrm{~d}$ and $120 \mathrm{~d}$. The design injection rate was set at $100 \mathrm{~m}^{3} / \mathrm{d}, 200 \mathrm{~m}^{3} / \mathrm{d}$, and $300 \mathrm{~m}^{3} / \mathrm{d}$. But during simulation, water breakthrough occurred at $300 \mathrm{~m}^{3} / \mathrm{d}$ of water injection (Figure 13).

After repeatedly adjusting the parameters, when the injection rate was set to $200 \mathrm{~m}^{3} / \mathrm{d}$, the bottom hole pressure reached the fracture opening pressure of $41.7 \mathrm{MPa}$, which was lower than the formation fracture pressure.

To give full play of segmented injection and production and optimize the injection and production system, segmented asynchronous injection and production, synchronous injection and production, and water huff and puff of actual well were simulated to predict 18 years of production. Comparing various indexes, the segmented asynchronous injection and production showed the best performance in recovery rate (Figure 14).

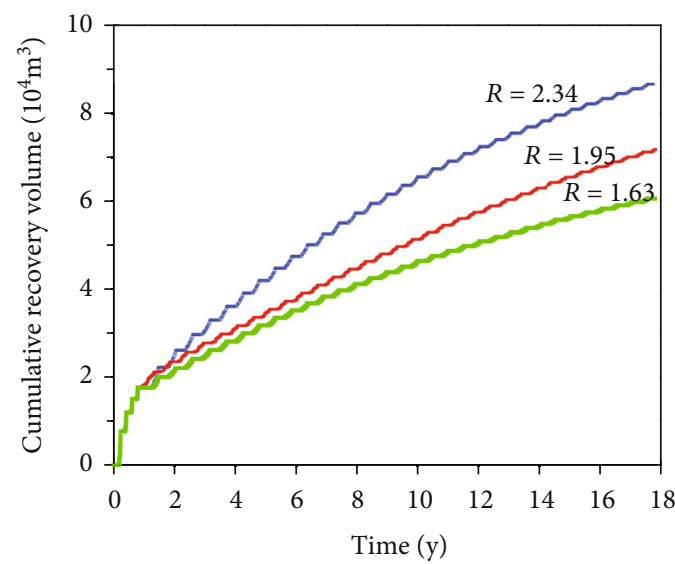

- Asynchronous injection and production

- Synchronous injection and production

- Water huff and puff

FIgURE 14: Cumulative recovery volume of different developing modes.

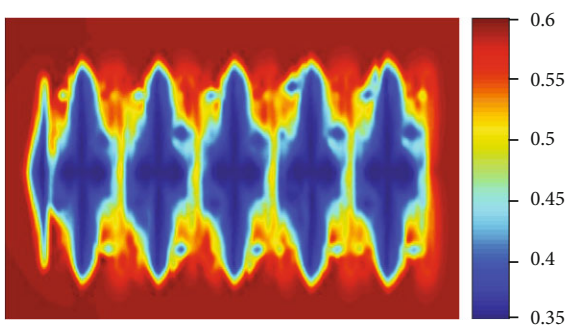

(a) Synchronous injection and production

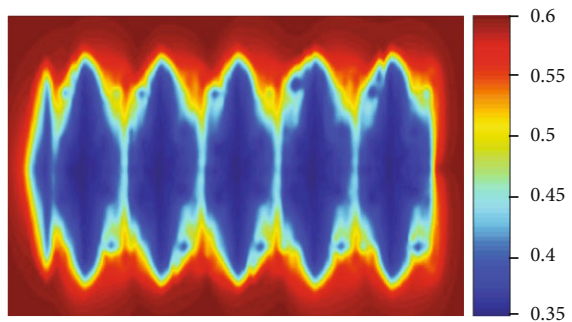

(b) Asynchronous injection and production

FIGURE 15: Oil saturation field of single well-segmented injection and production.

The simulation result of remaining oil distribution of bottom of Well M56-151H shows a relative lower saturation by using segmented asynchronous injection and production (Figure 15(b)), suggesting a sufficient production of the remaining oil after 17 years of production with segmented asynchronous injection and production following 4 rounds 


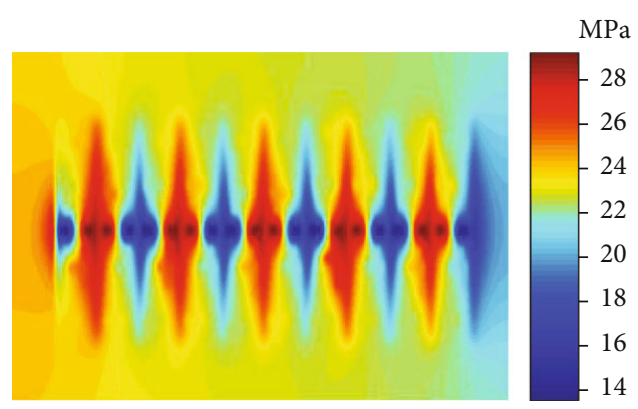

(a) Synchronous injection and production

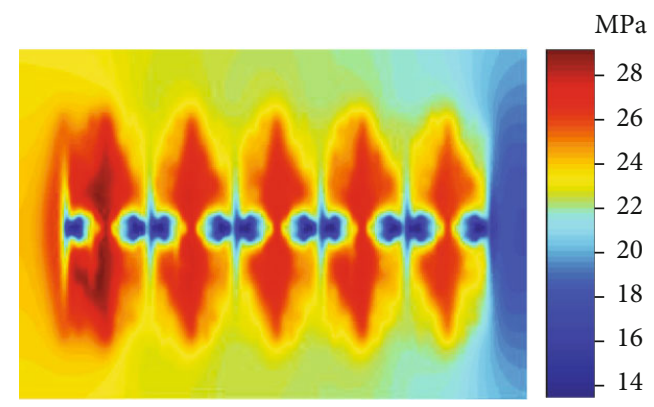

(b) Asynchronous injection and production

FIGURE 16: Pressure distribution of single well-segmented injection and production.

of water huff and puff. The simulated formation pressure shows a relative higher pressure using this developing mode, suggesting sufficient energy after 18 years of production (Figure 16(b)).

The significant enhancement in oil recovery brought by segmented injection with surfactant is caused by the fact that water injection induces propagation of natural fractures and thereby forms favorable channels. The surfactant reduces the interfacial tension, thus reducing the boundary layer resistance, enlarging the contact area between injected water and matrix, and realizing the full potential of radial displacement and imbibition.

\section{Conclusion}

(1) Based on the energy balance principle of fracture mechanics, the fracture propagation and closure length were deduced considering the characteristics of type I and type II composite fractures. In the effective displacement system formed by water injection induced fractures, interaction does not only take place within fluids, a resistance due to boundary layer effect also existing between fluid and matrix

(2) In the light of the complex formation characteristics of tight fractured reservoirs, the process of natural fracture propagation and distribution of remaining oil in a fractured tight reservoir were simulated based on the theory of radial displacement and imbibition in dynamic fracture network. With the simulation results, the sections where natural fractures are well developed and dynamic fracture network is formed were set as water injection end, while the ones where fractures are poorly developed were set as oil production end

(3) The segmented injection and production could give full play to both the static imbibition during the injection shutdown and soaking and the radial displacement and dynamic imbibition in the dynamic fracture system formed by natural fracture propagation. By this way, the crude oil in the matrix is replaced into the seepage channel and recovered by displacement. When designing interval spacing, it is important to consider the degree of fracture propagation and closure and to optimize the work regime to ensure that water channeling does not occur. The addition of surfactant promoted the displacement and imbibition of the injected water in the fracture network

(4) The developing modes of segmented synchronous injection and production and asynchronous injection and production were discussed. The simulated 18year cumulative recovery of both the modes was improved, and that of synchronous injection and production was relatively higher. The calculated propagation lengths of fractures were shorter than well spacing and interval spacing, and no water channeling happened. The remaining oil was sufficiently recovered by using segmented synchronous injection and production, which verified the feasibility of this developing mode to effectively enhance oil recovery

\section{Data Availability}

The data used to support the findings of this study are included within the article.

\section{Conflicts of Interest}

The authors declare that there is no conflict of interest.

\section{Acknowledgments}

The authors are grateful for the financial support from the National Natural Science Foundation of China (11872073).

\section{References}

[1] Y. Jun, L. Lijun, S. Hai et al., "Numerical simulation and mechanism analysis of water huff and puff process in complex fractured tight oil reservoirs," Journal of China University of Petroleum (Natural Science Edition), vol. 43, no. 5, pp. 108$117,2019$.

[2] F. Jianming, C. Wang, and Q. Xuefeng, "Development and practice of water flooding huff-puff in tight oil horizontal well, Ordos Basin: a case study of Yanchang Formation Chang 7 oil layer," Acta Petroleum, vol. 40, no. 6, pp. 706-715, 2019.

[3] J. Hagoort, Water flood-Induced Hydraulic Fracturing, [Ph.D. Thesis], Delft Technical University, Delft, The Netherlands, 1981. 
[4] Y. Wang, S. Cheng, N. Feng, Y. He, and H. Yu, "The physical process and pressure-transient analysis considering fractures excessive extension in water injection wells," Journal of Petroleum Science \& Engineering, vol. 151, no. 151, pp. 439-454, 2017.

[5] Y. Wang, S. Cheng, N. Feng et al., "Semi-analytical modeling for water injection well in tight reservoir considering the variation of waterflood - induced fracture properties - case studies in Changqing Oilfield, China," Journal of Petroleum Science \& Engineering, vol. 159, no. 159, pp. 740-753, 2017.

[6] Y. Wang, S. Cheng, K. Zhang, Y. He, and H. Yu, "Pressuretransient analysis of water injectors considering the multiple closures of waterflood-induced fractures in tight reservoirs: Case studies in Changqing Oilfield, China," Journal of Petroleum Science \& Engineering, vol. 172, no. 172, pp. 643-653, 2019.

[7] G. Luo, C. Ehlig-Economides, and M. Nikolaou, "Advantage of miscible fluid injection and tight oil production through a single-well alternating production-injection procedure over other single-well EOR methods," Journal of Petroleum Science and Engineering, vol. 199, article 108091, 2021.

[8] Y. Tie, L. Wei, and B. Xueliang, "Mechanical analysis of closing shape of crack induced by waterfrac treatment," Chinese Journal of Rock Mechanics and Engineering, vol. 28, no. S2, pp. 3471-3476, 2009.

[9] L. Luo, S. Cheng, and J. Lee, "Semi-analytical model for characterization of anomalous linear-flow behavior in partiallypropped fractured wells," Journal of Petroleum Science and Engineering, vol. 200, article 108380, 2021.

[10] S. Xu, X. A. Yue, J. Hou, and B. X. Wang, "Influence of boundary-layer fluid on the seepage characteristic of lowpermeability reservoir," Journal of Xi'an Shiyou University (Natural Science Edition), vol. 22, no. 2, pp. 26-28, 2007.

[11] W. Liu, J. Liu, L. Sun, Y. Li, and X. Lan, "Influence of fluid boundary layer on fluid flow in low permeability oilfields," Science and Technology Review, vol. 29, no. 22, pp. 42-44, 2011.

[12] Z. Xueling, Percolation Theory Research of Weakly Compressible Fluid Flow considering Wall-Liquid Interaction, [Ph.D. Thesis], Beijing University of Science and Technology, Beijing, 2015.

[13] L. Yang, Study of Microscale Nonlinear Flow Characteristics and Flow Resistance Reducing Methods, [Ph.D. Thesis], Institute of Fluid Mechanics, Chinese Academy of Sciences, Beijing, 2010.

[14] B. Wei, J. Liu, X. Zhang, and W. Pu, "Advances of enhanced oil recovery method and theory in tight reservoirs," Journal of Southwest Petroleum University, vol. 43, no. 1, pp. 91-102, 2021.

[15] Q. Zhengshan, Z. Jianliang, and J. Xie, "Experiment on enhanced oil recovery by surfactant injection oil displacement system in tight sandstone reservoirs," Fault Block Oil and Gas Field, vol. 27, no. 5, pp. 628-632, 2020.

[16] Y. Wang, S. Cheng, K. Zhang, and L. F. Ayala, "Investigation on the transient pressure response of water injector coupling the dynamic flow behaviors in the wellbore, waterfloodinduced fracture and reservoir: semi-analytical modeling and a field case," International Journal of Heat \& Mass Transfer, vol. 130, no. 130, pp. 668-679, 2019.

[17] Z. Xueling, K. Songya, S. Yutao et al., "Research progress on the nonlinear seepage characteristics of tight oil in nanomircon porous media," China Offshore Oil and Gas, vol. 31, no. 4, pp. 102-112, 2019.
[18] L. Gao, Z. Yang, and Y. Shi, "Experimental study on spontaneous imbibition chatacteristics of tight rocks," Advances in GeoEnergy Research, vol. 2, no. 3, pp. 292-304, 2018.

[19] L. Yang, S. Wang, C. Jianchao, Y. Gan, and A. Salama, "Main controlling factors of fracturing fluid imbibition in shale fracture network," Capillarity, vol. 1, no. 1, pp. 1-10, 2018.

[20] F. Ghasemi, M. Ghaedi, and M. Escrochi, "A new scaling equation for imbibition process in naturally fractured gas reservoirs," Advances in Geo-Energy Research, vol. 4, no. 1, pp. 99-106, 2020.

[21] H. Zhongying, Research on Mechanics Mechanism in Refracturing and Its Applications, [Ph.D. Thesis], China University of Petroleum (East China), Qingdao, 2012.

[22] J. Bingyu, J. Yang, and L. Zhiguo, "Numerical simulation calculation of changing the direction of liquid flow," Daqing Petroleum Geology and Development, vol. 2, pp. 73-74, 1994.

[23] Z. Wu, L. Li, Z. Jialiang, Y. Yiqun, W. Junwen, and Z. Yuan, "Research on transformation of waterflooding development mode in low permeability oil reservoirs-Taking GD6X1 Block of Kongnan in Dagang Oilfield as an example," Petroleum Geology and Recovery Efficiency, vol. 2, pp. 1-7, 2021.

[24] F. Wang, Z. Fanchao, and Z. Jiuyu, "A mathematical model of displacement and imbibition of low-permeability/tight reservoirs and its application," Acta Petroleum, vol. 41, no. 11, pp. 1396-1405, 2020.

[25] S. Cheng, D. Lian, H. Yu et al., "Injection-production technique for the same horizontal well," Daqing Petroleum Geology and Development, vol. 38, no. 4, pp. 51-60, 2019.

[26] Z. Jiansheng, Fracture Mechanics and Fracture Physics, Huazhong University of Science and Technology Press, Wuhan, 2004.

[27] T. Shibin, H. Runqiu, and T. Chunan, "Effect of T-stress on crack growth path in rock and fracture strength," Rock and Soil Mechanics, vol. 37, no. 6, pp. 1521-1529, 2016.

[28] L. Hongyan, "Initiation mechanism of cracks of rock in compression and shear considering T-stress," Chinese Journal of Geotechnical Engineering, vol. 41, no. 7, pp. 1296-1302, 2019.

[29] G. Hui, S. Chen, Y. Wang, and F. Gu, "The effect of hydraulicnatural fracture networks on the waterflooding development in a multilayer tight reservoir: case study," Geofluids, vol. 2021, 15 pages, 2021.

[30] E. W. Washburn, "The dynamics of capillary flow," Physics Review, vol. 17, no. 3, pp. 273-283, 1921.

[31] J. I. Jiyang, X. U. Haitao, T. I. Shansi et al., "Influence of correction of interfacial tension and wetting angle to the pore size distribution of shale by means of high pressure mercury porosity: a case study of Qingshankou Formation in Songliao Basin," Geoscience, vol. 32, no. 1, pp. 191-197, 2018. 